\title{
Erratum to: Sphingosine-1-phosphate induces differentiation of cultured renal tubular epithelial cells under Rho kinase activation via the S1P2 receptor
}

\author{
Sho Ishizawa · Junko Takahashi-Fujigasaki • Yasushi Kanazawa • \\ Keiichiro Matoba - Daiji Kawanami - Tamotsu Yokota - Takeo Iwamoto • \\ Naoko Tajima $\cdot$ Yoshinobu Manome $\cdot$ Kazunori Utsunomiya
}

Published online: 29 March 2014

(C) Japanese Society of Nephrology 2014

\section{Erratum to: Clin Exp Nephrol \\ DOI 10.1007/s10157-014-0933-x}

Figure 5e appeared incorrectly in the article cited above.

The correct figure is shown here.

The online version of the original article can be found under doi:10.1007/s10157-014-0933-x.

\footnotetext{
S. Ishizawa $(\bowtie) \cdot$ Y. Kanazawa $\cdot$ K. Matoba $\cdot$ D. Kawanami ·

T. Yokota $\cdot$ N. Tajima $\cdot$ K. Utsunomiya

Division of Diabetes, Metabolism and Endocrinology,

Department of Internal Medicine, The Jikei University School of

Medicine, 3-25-8 Nishishinbashi, Minato-ku, Tokyo 105-8461,

Japan

e-mail: ishizawa@jikei.ac.jp

J. Takahashi-Fujigasaki

Division of Neuropathology, The Jikei University School of

Medicine, 3-25-8 Nishishinbashi, Minato-ku, Tokyo 105-8461,

Japan

T. Iwamoto

Core Research Facilities, The Jikei University School of Medicine, 3-25-8 Nishishinbashi, Minato-ku, Tokyo 105-8461,

Japan

\section{Y. Manome}

Department of Molecular Cell Biology, The Jikei University

School of Medicine, 3-25-8 Nishishinbashi, Minato-ku,

Tokyo 105-8461, Japan
} 

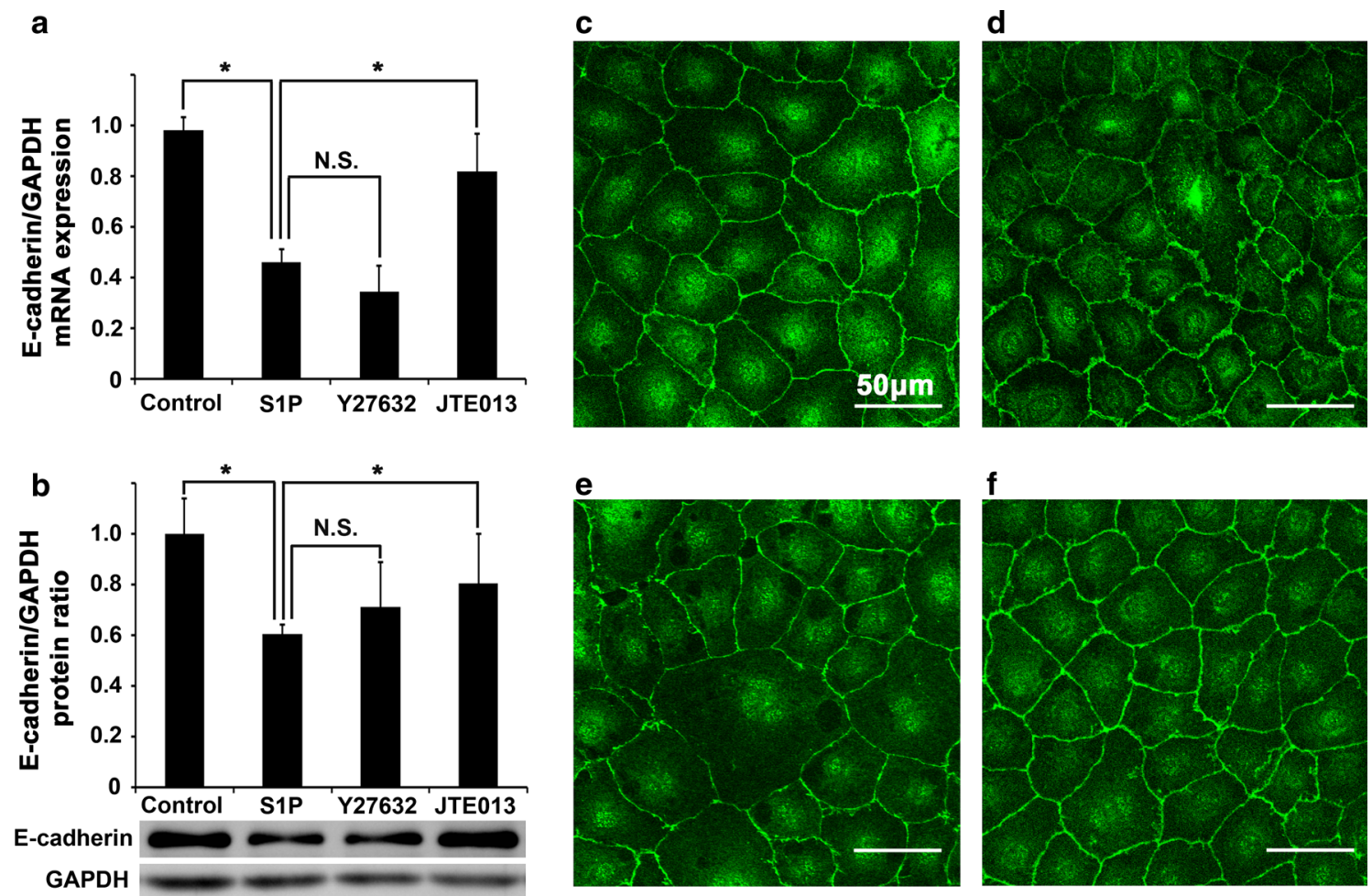

Fig. 5 Effect of Y-27632 and JTE013 on S1P-induced E-cadherin mRNA expression. After starvation in serum-free media for $24 \mathrm{~h}$, NRK52E cells were stimulated with S1P $(1 \mu \mathrm{M})$ with or without pretreatment for $1 \mathrm{~h}$ with Y-27632 $(10 \mu \mathrm{M})$ or JTE013 $(10 \mu \mathrm{M})$. a After a 4-h stimulation with S1P, RNA was extracted, and E-cadherin mRNA was analyzed by real-time RT-PCR with GAPDH mRNA as the internal standard. b Total protein was prepared and subjected to SDS-PAGE and Western blot analysis with antibodies against E-cadherin or GAPDH as the internal standard. The results represent the mean $\pm \mathrm{SD}$ of four separate experiments. $* P<0.05$. cf Fluorescent immunocytochemistry for E-cadherin. c The cells were grown on coverslips to $80 \%$ confluence then treated with BSA, df S1P $(1 \mu \mathrm{M})$ stimulation for $10 \mathrm{~h}$, e Y27632 $(10 \mu \mathrm{M})$ and f JTE013 $(10 \mu \mathrm{M})$ pretreatment for $1 \mathrm{~h}$ before S1P stimulation. Immunofluorescence was performed using mouse monoclonal anti-E-cadherin and Alexa488-labeled goat anti-mouse antibodies. E-cadherin expression in the cells was visualized and photographed by fluorescence microscopy at a $\times 400$ magnification 